\title{
Did design flaws doom the LHC?
}

\section{Catastrophic failure that caused accelerator shutdown was not a freak accident, says project physicist.}

Running more than a year behind schedule and at half its intended energy, the world's most powerful particle accelerator is slated to begin its first full scientific run this week. Along with relief, the occasion is bringing some soul-searching. One senior scientist who helped to build the Large Hadron Collider (LHC) at CERN, Europe's particle-physics laboratory near Geneva, Switzerland, is claiming that the cause of the delay - a major accident in 2008 - could have been avoided.

"Any technical fault is a human fault," says Lucio Rossi, a physicist

\section{"What we have to do is learn from our mistakes and make it better."}

cables developed a small amount of resistance, which warmed the connection until the cables - cooled by liquid helium to superconducting temperatures - lost their ability to carry current. Thousands of amps arced through the machine, blowing a hole in its side and releasing several tonnes of liquid helium. The expanding helium gas created havoc, spewing soot into the machine's ultraclean beamline and ripping magnets from their stands. Repairs took more than a year, and the LHC successfully restarted last November.

An investigation revealed that technicians had not properly soldered the cables together. With tens of thousands of such connections, it is perhaps inevitable that some were faulty, Rossi says, but design flaws worsened the problem. The silver-tin solder that was used melted at high temperatures and did not flow easily into the cable joints. Moreover, workers did not adequately check to see if each connection was electrically secure. Sensors to detect an overheating circuit, which might have helped prevent the accident, were not installed until after it happened.

Worse, says Rossi, when the wires were originally joined, the same silver-tin solder was used to connect them to an adjacent copper stabilizer, meant to provide an escape route for current in the event of a failure. That step risked reheating and destroying the original connection, he says. Making the second connection to the stabilizer with a different type of solder that had a lower melting point could have avoided the problem. Lyn Evans, who oversaw the LHC from 1994 to 2009, says that the idea was considered and rejected because the alternative solder contained lead, a hazard to workers.

A detailed analysis last summer revealed several more bad connections, and CERN now says that it will take a year to correct the problem throughout the machine. As a result, the LHC will not run at its full collision energy of 14 teraelectronvolts $\left(10^{12} \mathrm{eV}\right)$ until around 2013.

Many LHC scientists involved say that the accident was a natural consequence of constructing such a large and unique machine. "I personally think he [Rossi] is a bit too harsh on himself and the management of the time," says Steve Myers, the current project head of the LHC. "In such a technically complicated project with tight schedules it is almost inevitable that things go wrong."

\section{Pebble-bed nuclear reactor gets pulled}

Hopes for the development of pebble-bed nuclear reactor technology, long held up as a safer alternative to conventional nuclear power, have suffered a blow. Last week, the South African government confirmed that it will effectively stop funding a long-term project to develop the technology.

The development company, Pebble Bed Modular Reactor (PBMR), based near Pretoria, says that it is now considering axing three-quarters of its 800 staff, about half of whom are scientists or engineers. "The resources available to the company will not sustain the current cost structure," the company says. The cuts could trigger an exodus of nuclear expertise from South Africa, although some argue that government funding has kept the project going for too long in the face of growing problems.

South Africa started to develop its pebble-bed reactor design in the mid-1990s, hoping that it would deliver cheap electricity and open up a lucrative export industry. It licensed the technology from Germany's Jülich Research Centre, which abandoned a working prototype reactor in 1991 after citing poor business opportunities.

Eskom, South Africa's main electricity generator, based in Johannesburg, set up the PBMR in 1999 to develop the technology into a economically viable reactor. "It caught the mood in South Africa, and the feeling among South Africans was that their technology was as good as anybody's," says Steve Thomas, an energy-policy researcher at the University of Greenwich, London. “This was their

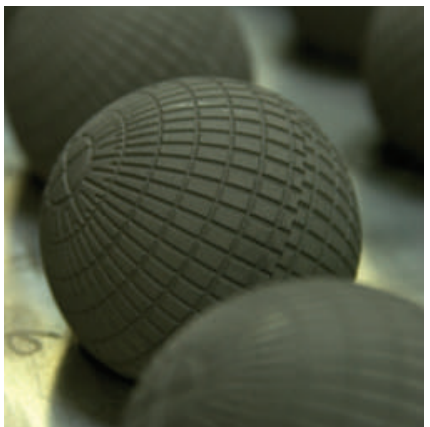

Bedtime for pebbles?

chance to show the world what they could do."

The proposed reactor would have used enriched uranium fuel embedded within tennis-ball-sized graphite spheres ('pebbles'). These should enable it to run at temperatures of between $750^{\circ} \mathrm{C}$ and $1,600^{\circ} \mathrm{C}$ yet resist a core meltdown even if the helium-gas coolant is lost, an attractive safety feature.

But several of the firm's biggest investors, including the utility firm Exelon in Chicago, Illinois, withdrew during the feasibility phase, which ended in 2004. In the four years up to March 2007, the South African government contributed 7.2 billion rands (US\$935 million) in funding, on the condition that the PBMR "attract additional investment through investors other than government, and that it secure a customer for its product", according to a government statement. However, despite a revised business model and product offering, the firm has been unable to do either of these, the government says. Funding was last week slashed to 11 million rands over the next three years, 
